Review began 02/02/2022 Review ended 02/06/2022 Published 02/08/2022

(c) Copyright 2022 Prakash et al. This is an open access article distributed under the terms of the Creative Commons Attribution License CCBY 4.0., which permits unrestricted use, distribution, and reproduction in any medium, provided the original author and source are credited.

\section{Inflammatory Cloacogenic Polyp: A Rare Benign Colorectal Polyp}

\author{
Neha Prakash ${ }^{1}$, Shiv J. Vyas ${ }^{2}$, Abdul Mohammed ${ }^{3}$, Nisheet Waghray ${ }^{4}$ \\ 1. Medicine, A.T. Still University, School of Osteopathic Medicine, Mesa, USA 2. Medicine, California Northstate \\ University, Elk Grove, USA 3. Hospital Medicine, Cleveland Clinic, Cleveland, USA 4. Gastroenterology and Hepatology, \\ Case Western Reserve University School of Medicine/Metrohealth Medical Center, Cleveland, USA
}

Corresponding author: Abdul Mohammed, mas.shariq@gmail.com

\begin{abstract}
Inflammatory cloacogenic polyps are a rare kind of benign polyp that is located in the anal transitional zone and rectum. We report the case of a 53-year-old male who underwent a diagnostic colonoscopy for a positive fecal immunochemical test. Two $7 \mathrm{~mm}$ polyps were found in the rectum with a pathological diagnosis of inflammatory cloacogenic polyp. The polyp was endoscopically resected. These polyps are associated with chronic inflammatory conditions such as Crohn's disease and colorectal tumors. Because of malignant transformation potential, inflammatory cloacogenic polyps are endoscopically removed.
\end{abstract}

Categories: Gastroenterology

Keywords: solitary rectal ulcer, mucosal prolapse, colorectal polyp, benign tumors, colonoscopy

\section{Introduction}

Inflammatory cloacogenic polyps are a rare type of anorectal polyp that usually arise in the anal transitional zone [1]. They share distinctive morphologic and histological characteristics with other disorders included in the mucosal prolapse syndromes. Given the paucity of literature regarding inflammatory cloacogenic polyps, the etiopathogenesis of these lesions is poorly defined. While a majority of patients have symptoms, $20 \%$ of cases remain asymptomatic [2]. We present a case of inflammatory cloacogenic polyp in an asymptomatic patient with a positive fecal immunochemical test (FIT) performed for colorectal cancer screening.

\section{Case Presentation}

\section{History}

A 53-year-old female with a history of low-grade papillary tumor of the bladder, cigarette smoking, and alcohol abuse was seen in the gastroenterology clinic for colorectal cancer screening. She denied any current symptoms of abdominal pain, nausea, vomiting, hematemesis, melena, hematochezia, constipation, diarrhea, tenesmus, fecal urgency, fevers, chills, loss of appetite, or weight loss. She had no family history of gastrointestinal malignancy or inflammatory bowel disease.

\section{Physical examination}

On physical exam, we did not elicit any abdominal tenderness. There was no organomegaly or abdominal distention. Normal bowel sounds were heard all over the abdomen. A direct rectal exam was positive for dark-colored stool on the gloved finger.

\section{Investigations}

Laboratory studies revealed a hemoglobin $12.2 \mathrm{~g} / \mathrm{dl}$, hematocrit 40\%, MCV $88.3 \mathrm{fL}$, platelet $368 \mathrm{k} / \mathrm{uL}$. She tested positive on a FIT and subsequently underwent a diagnostic colonoscopy two weeks later. The colonoscopy revealed two sessile $7 \mathrm{~mm}$ polyps in the rectum (Figure 1). The sigmoid colon had a total of seven polyps ranging in size from $15 \mathrm{~mm}$ to $25 \mathrm{~mm}$ with all of the polyps removed using snare polypectomy. Histopathology findings demonstrated prolapse-induced inflammatory cloacogenic polyp in the rectum (Figure 2). Histopathology of the polyps in the sigmoid colon was consistent with tubular adenoma and serrated adenoma. 


\section{Cureus}

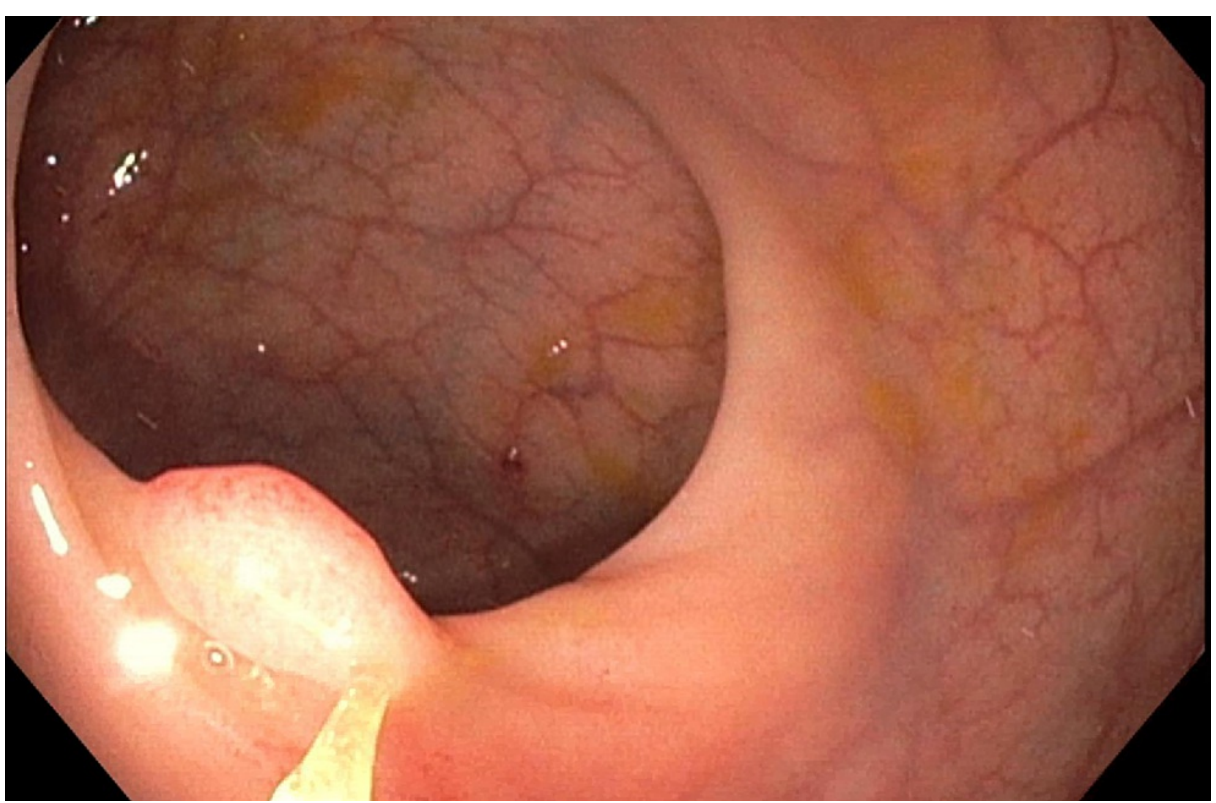

FIGURE 1: Endoscopic appearance of inflammatory cloacogenic polyp on diagnostic colonoscopy

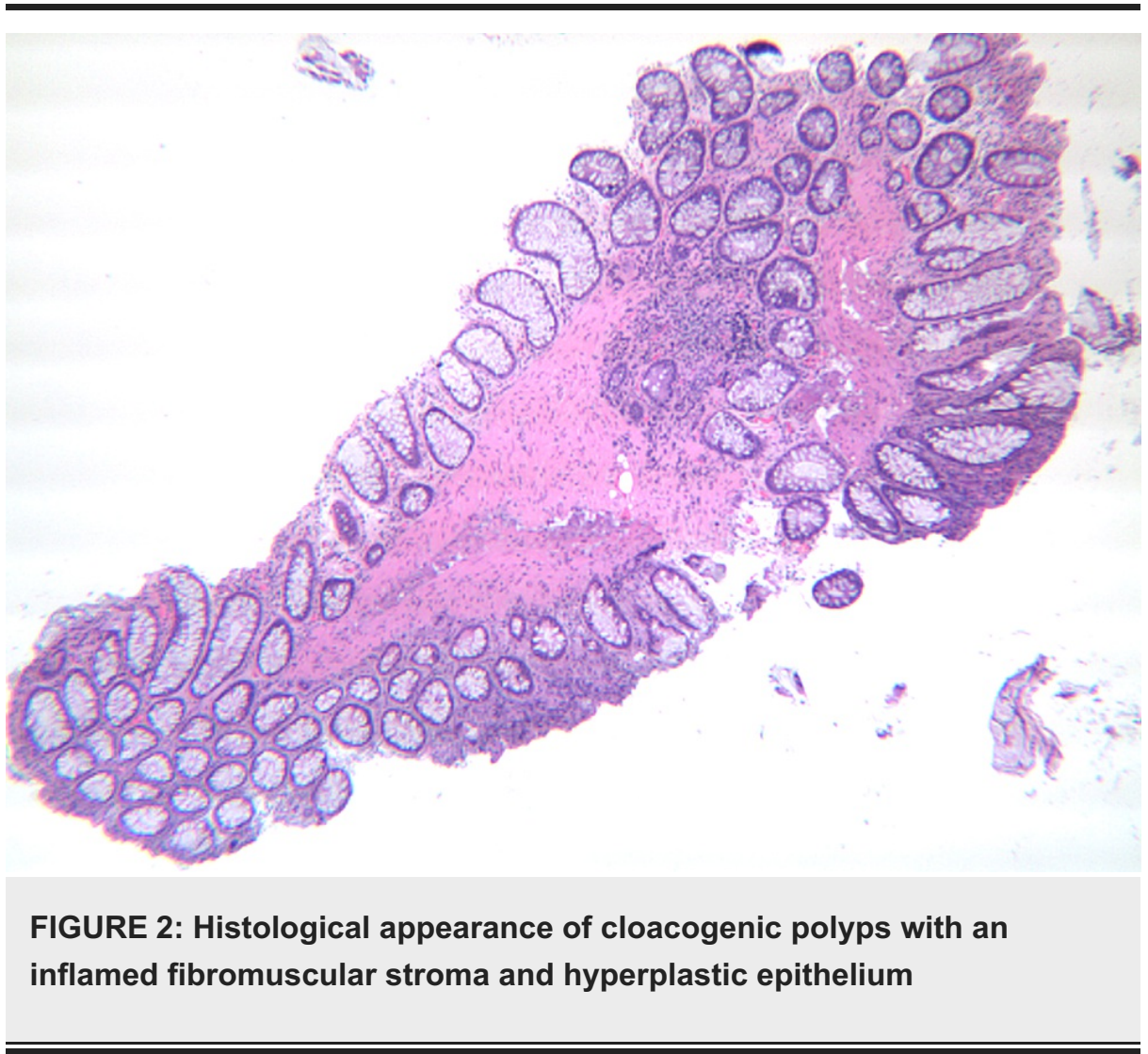

\section{Treatment plan}

After polyp resection, the patient continues to be asymptomatic. Since cloacogenic polyps are benign, we did not pursue any further management. However, due to the presence of a tubular adenoma, the patient is scheduled to follow up in the gastroenterology clinic for endoscopic surveillance.

\section{Discussion}

Inflammatory cloacogenic polyps were first described by Lobert et al. in 1981 [1]. They are single or multiple, more pedunculated than sessile, $10 \mathrm{~mm}$ to $50 \mathrm{~mm}$ in size, located at the anorectal junction [3]. An 
inflammatory cloacogenic polyp may morphologically mimic hemorrhoid, solitary rectal ulcer, villous adenoma, or anorectal carcinoma. Hence, a histopathological evaluation is essential to distinguish it from carcinoma and squamous metaplasia of chronically prolapsing hemorrhoids [4]. Histological findings are a tubulovillous growth pattern and irregular-shaped crypts displaced into the submucosa, surrounded by a prominent fibromuscular stroma with superficial ulceration. There is a distinct mixed inflammatory infiltrate of the fibromuscular stroma. The cysts are lined by colonic epithelium, without dysplasia [1]. The diagnosis of inflammatory cloacogenic polyp is confirmed by the presence of squamous or transitional epithelium overlying the polyp. Inflammatory cloacogenic polyp shares the hallmark histological feature of crypts displaced into the submucosa with the solitary rectal syndrome. However, unlike inflammatory cloacogenic polyps that are found in the anal transitional zone, solitary rectal ulcers occur in the rectum.

Cloacogenic polyps are relatively more common in women between 40 and 60 years of age [4]. Hematochezia is the most common clinical presentation of cloacogenic polyps. In addition to rectal bleeding, other symptoms associated with inflammatory cloacogenic polyps are constipation, tenesmus, excessive straining, anal swelling, and anal itching. However, $20 \%$ of patients can also be asymptomatic [2].

The pathophysiology of cloacogenic polyps remains unclear. However, since it shares histological features with other causes of mucosal prolapse syndromes, such as solitary rectal ulcer syndrome, repeated mucosal ischemia and regeneration are postulated to play a role in pathogenesis [2,5]. Solitary rectal ulcer syndrome is associated with excessive straining on defecation, the inability of the pelvic floor musculature to relax, leading to mucosal prolapse and ischemia [6]. Although half of the inflammatory cloacogenic polyps are associated with mucosal prolapse, the effect of stercoral forces in the formation of cloacogenic polyps is unknown.

Inflammatory cloacogenic polyps have been reported in adults with various gastrointestinal disorders, including Crohn's disease, malabsorptive states, diverticulosis, colorectal tumors, and hemorrhoids. However, a causal relationship between the diseases and cloacogenic polyps has not been identified. Inflammatory cloacogenic polyps have also been associated with dysplastic lesions in the anus and anal intraepithelial neoplasia [5,7]. Human papillomavirus, routinely implicated in anorectal neoplasms, is also related to inflammatory cloacogenic polyps [7].

Endoscopic or surgical resection of lesions in addition to a high fiber diet is the preferred treatment $[3,4]$. Routine endoscopic surveillance is highly encouraged after polypectomy because of the increased risk of recurrence and malignant transformation [7].

\section{Conclusions}

In conclusion, inflammatory cloacogenic polyps are rare, benign, polypoidal lesions that can be found on colonoscopy. Since they can be mistaken for anorectal neoplasm or hemorrhoids, endoscopists need to be familiar with inflammatory cloacogenic polyps. Active surveillance after resection is necessary because of their high risk of recurrence and potential for malignant transformation.

\section{Additional Information \\ Disclosures}

Human subjects: Consent was obtained or waived by all participants in this study. Conflicts of interest: In compliance with the ICMJE uniform disclosure form, all authors declare the following: Payment/services info: All authors have declared that no financial support was received from any organization for the submitted work. Financial relationships: All authors have declared that they have no financial relationships at present or within the previous three years with any organizations that might have an interest in the submitted work. Other relationships: All authors have declared that there are no other relationships or activities that could appear to have influenced the submitted work.

\section{References}

1. Lobert PF, Appelman HD: Inflammatory cloacogenic polyp. A unique inflammatory lesion of the anal transitional zone. Am J Surg Pathol. 1981, 5:761-6.

2. Tendler DA, Aboudola S, Zacks JF, O'Brien MJ, Kelly CP: Prolapsing mucosal polyps: an underrecognized form of colonic polyp--a clinicopathological study of 15 cases. Am J Gastroenterol. 2002, 97:370-6. 10.1111/j.1572-0241.2002.05472.x

3. Levey JM, Banner B, Darrah J, Bonkovsky HL: Inflammatory cloacogenic polyp: three cases and literature review. Am J Gastroenterol. 1994, 89:438-41.

4. Shih CM, Tseng HH, Tu UC: Inflammatory cloacogenic polyp of anus: report of three cases . Zhonghua Yi Xue Za Zhi (Taipei). 1990, 45:69-74.

5. Parfitt JR, Shepherd NA: Polypoid mucosal prolapse complicating low rectal adenomas: beware the inflammatory cloacogenic polyp!. Histopathology. 2008, 53:91-6. 10.1111/j.1365-2559.2008.03035.x

6. Saul SH: Inflammatory cloacogenic polyp: relationship to solitary rectal ulcer syndrome/mucosal prolapse and other bowel disorders. Hum Pathol. 1987, 18:1120-5. 10.1016/s0046-8177(87)80379-9

7. Hanson IM, Armstrong GR: Anal intraepithelial neoplasia in an inflammatory cloacogenic polyp . J Clin 


\section{Cureus}

Pathol. 1999, 52:393-4. 10.1136/jcp.52.5.393 